\title{
The Effect of Visually Masked Syllable Primes on the Naming Latencies of Words and Pictures
}

\author{
Niels O. Schiller \\ Max Planck Institute for Psycholinguistics, Nijmegen, The Netherlands
}

\begin{abstract}
To investigate the role of the syllable in Dutch speech production, five experiments were carried out to examine the effect of visually masked syllable primes on the naming latencies for written words and pictures. Targets had clear syllable boundaries and began with a CV syllable (e.g., ka.no) or a CVC syllable (e.g., kak.tus), or had ambiguous syllable boundaries and began with a CV[C] syllable (e.g., ka[pp]er). In the syllable match condition, bisyllabic Dutch nouns or verbs were preceded by primes that were identical to the target's first syllable. In the syllable mismatch condition, the prime was either shorter or longer than the target's first syllable. A neutral condition was also included. None of the experiments showed a syllable priming effect. Instead, all related primes facilitated the naming of the targets. It is concluded that the syllable does not play a role in the process of phonological encoding in Dutch. Because the amount of facilitation increased with increasing overlap between prime and target, the priming effect is accounted for by a segmental overlap hypothesis. ๑1 1998 Academic Press

Key Words: Speech production; phonological encoding; syllables; masked priming; WEAVER model; Dutch.
\end{abstract}

Psycholinguistic evidence suggests that the syllable may be a functional unit in the processing of speech, at least in some languages. In speech perception, recent research has shown that sublexical units such as the syllable can be crucial in speech segmentation and recognition (for recent reviews see Dupoux, 1993; Nusbaum \& DeGroot, 1990; Segui, Dupoux, \& Mehler, 1990). In speech production, evidence for the role of the syllable is much weaker. It has often been claimed that segmental speech errors are sensitive to syllable structure, in that onsets exchange with other onsets, codas exchange with other codas, and so on (for English see MacKay, 1970; Shattuck-Hufnagel, 1979; Stemberger, 1982; for Dutch see Nooteboom,

The author thanks John Nagengast for his technical support during the experiments and Inge Doehring for drawing the pictures used in Experiment 2. He is grateful to Antje Meyer, Ardi Roelofs, Pim Levelt, Jonathan Grainger, Ludovic Ferrand, and two anonymous reviewers for their helpful comments on the manuscript.

Address correspondence and reprint requests to Niels O. Schiller, Cognitive Neuropsychology Laboratorium, Department of Psychology, Harvard University, 33 Kirkland Street, William James Hall 918, Cambridge, MA 02138. E-mail: nschille@wjh.harvard.edu.
1969; for German see Berg, 1988). However, since most exchange errors occur in syllable onset position it may well be that the supposed syllable structure effect is in fact an onset effect (Shattuck-Hufnagel, 1987, 1992; Meyer, 1992).

Knowing the number of syllables of a target word without being able to access its segments may be another indirect source of evidence for syllables in speech production. Studies of the tip-of-the-tongue (TOT) experience showed that participants are often able to report the number of syllables in the target word when they are in a TOT state (Burke et al., 1991; Lovelace, 1987; but see Caramazza \& Miozzo, 1997). However, as Brown (1991) pointed out, this may at least partly reflect the fact that the chance of guessing correctly is relatively high because the number of syllables in a word is quite restricted. Furthermore, since the number of syllables of a word equals the number of vowels, it may be that what participants are actually able to report is the number of the acoustically salient vowels.

A related account can also be given to explain the number-of-syllables effect on pronunciation latency. Klapp, Anderson, and Berrian (1973) 
found that English five-letter words were named significantly faster when they were monosyllabic than when they were bisyllabic although the words did not differ in response duration as shown by Klapp and Erwin (1976). This finding was recently replicated by Santiago et al. (1996) when onset complexity was controlled. Klapp (1974) replicated the number-of-syllables effect with two-digit number words. Other researchers, however, did not find such an effect (Forster \& Chambers, 1973; Frederiksen \& Kroll, 1976). In fact, it may be argued that it is not the number of syllables to be phonologically encoded that is responsible for the effect but the number of vowels that have to be encoded.

Jared and Seidenberg (1990) investigated the effect of presenting words syllable by syllable. They obtained an increase in naming latencies for high- and low-frequency exception words relative to a whole-word presentation. Syllabic presentation had no effect for regular words. This suggests that the production of exception words normally takes into account information that goes beyond the boundaries of individual syllables and that these words are not generated on a syllable-by-syllable basis.

From meta-linguistic tasks, however, there is ample evidence suggesting that syllables may be units of speech production. Syllables are one of the linguistic units that are often manipulated in naturally occurring word games (Hombert, 1986; Lefkowitz, 1991; see Bagemihl, 1995 for a review) and in backward talking (Cowan et al., 1982; Cowan, Braine, \& Leavitt, 1985). Under laboratory conditions, certain aspects of syllable structure and syllabification have been investigated, revealing further evidence for the syllable as a psycholinguistic unit (Bruck, Treiman, \& Caravolas, 1995; Fallows, 1981; Fowler, Treiman, \& Gross, 1993; Gillis \& de Schutter, 1996; Schiller, Meyer, \& Levelt, 1997; Treiman, 1983, 1986; Treiman \& Danis, 1988; Treiman et al., 1995; Treiman \& Zukowski, 1990, 1996; Wheeldon \& Levelt, 1995).

Recently, two studies have been reported in the literature that found clear syllabic effects in speech production. Ferrand, Segui, and Grainger (1996) studied the effect of masked syllable primes in a naming task with French materials. They obtained reliable facilitation in word, nonword, and picture naming when prime and target shared the first syllable relative to a condition where they shared a string of segments of equal length that was either longer or shorter than the first syllable. In a control experiment using a visual lexical decision task-a task that could be performed without output of the phonological form of the target- the syllable priming effect disappeared. This supported their hypothesis that the syllable priming effect arises during the creation of form representations required for overt naming. Ferrand et al. (1996) concluded that the syllable is a unit in speech production.

Given the existing evidence for the role of the syllable in French speech perception (Mehler et al., 1981; Pallier et al., 1993), this result may not come as a surprise. However, recently Ferrand, Segui, and Humphreys (1997) replicated these results with English materials. Syllable structure in English is less clear than in French because English has ambisyllabic consonants, e.g., the intervocalic $/ \mathrm{n} / \mathrm{in}$ a word like tonic /to[n]Ik/. ${ }^{1}$ Ferrand et al. (1997) hypothesized that $\mathrm{CV}$ and CVC primes (e.g., to and ton) should not yield significantly different priming effects for $\mathrm{CV}[\mathrm{C}]$ targets such as tonic, whereas the naming of CVC targets such as tonsil /ton.sI1/ should be facilitated only by a CVC but not by a $\mathrm{CV}$ prime. This hypothesis was confirmed by the data. In a lexical decision task the syllable priming effect disappeared. Furthermore, Ferrand et al. showed that English CV target words such as tomato /to.max.tou/ could be primed with $\mathrm{CV}$ but not with CVC primes. The overall conclusion of Ferrand et al. (1997) is that-just as in French-the syllable constitutes as unit of speech production in English.

Under the assumption that the masked priming paradigm taps into early stages of phonological encoding, the results of Ferrand et al. $(1996,1997)$ stand in contradiction with speech production models that assume that the syllable

\footnotetext{
${ }^{1}$ Throughout the article, ambisyllabic consonants appear between square brackets and syllable boundaries are marked by dots.
} 
structure of a word is not stored in the lexicon. In the following I will discuss one such model in more detail. In Levelt's (1992, 1993; Levelt, Roelofs, \& Meyer, in press; Levelt \& Wheeldon, 1994) model of phonological encoding, syllabification is a relatively late process during speech production. Syllables are created when individual segments that are unspecified for syllable position are associated to metrical frames or ordered strings of syllable slots marked for stress. This segment-to-frame association process precedes overt articulation and is based on general syllabification rules. The resulting phonetic surface syllables are called speech syllables (Schiller et al., 1996).

Speech syllables are articulatory motor units in Levelt's model of speech production. Crompton (1981) and Levelt (1989) assumed that there is a library of articulatory routines for syllables that is accessed during the process of speech production. Levelt and Wheeldon (1994) further developed this idea into a so-called mental syllabary. Instead of generating the sound representation of a word form on the basis of segmental information coded at the phonological level, they assumed that speech syllable specifications can be used to access precompiled syllabic motor programs in a mental syllabary. Access to such a syllabary could greatly reduce the computational load on the speech production system. Indeed, $85 \%$ of all syllable tokens in Dutch and German and $80 \%$ of all syllable tokens in English can be produced with the 500 most frequent syllable types in the respective language, which makes the idea of a separate store for (high-frequency) syllables very attractive (Levelt \& Schiller, in press; Schiller, 1997; Schiller et al., 1996).

Contrary to the assumption of on-line syllabification in Levelt's model, Dell's (1986) model assumed that syllables are stored in the lexicon. Furthermore, Dell (1988) proposed that more structural information such as the distribution on consonants and vowels or $C V$ structure of a lexical item may be represented explicitly. However, the evidence for the explicit representation of the CV structure is controversial. In two experiments, Meijer (1996) found significant facilitatory effects in a translation naming task for monosyllabic and bisyllabic items when targets and primes shared CV structure as compared to a condition when primes had a different CV structure. However, a closer inspection of the materials, which is reported in Meijer (1994, p. 133), shows that bisyllabic targets and primes did not always share exactly the same CV structure. Furthermore, in another experiment Meijer (1994) failed to replicate the effect of CV structure priming with monosyllables. In the third experiment of the Meijer (1996) study, targets and primes had the same or different vowel lengths (V or VV), but no effect of otherwise shared CV structure was obtained. Therefore, the evidence for stored CV structure presented in Meijer (1996) is rather weak, especially if one additionally considers that Roelofs and Meyer (1998) did not find an effect of shared $\mathrm{CV}$ structure using the implicit priming paradigm (Meyer, 1990, 1991).

The role of the CV structure in phonological encoding was also investigated by Sevald, Dell, and Cole (1995). They found that sequences of nonwords were produced faster when the monosyllables had the same CV structure as the first syllable of the disyllable than when this was not the case. However, as Roelofs and Meyer (1998) argue, it is not clear whether the CV structure effect arises during the creation of the phonological representation, as argued by Sevald et al. (1995), or during the retrieval of articulatory motor programs. Therefore, this study cannot be considered as clear evidence for the claim that $\mathrm{CV}$ structure is explicitly represented.

To test the "late syllabification" perspective taken in Levelt's model, Baumann (1995) investigated the time course of syllabification during word form encoding in Dutch. In a series of priming experiments using a semantic-associate learning task, she studied the influence of interfering auditory stimuli on the production of different types of verb forms. In all of her experiments there were significant facilitation effects when verb form targets were preceded by phonologically related syllable primes (as compared to an unrelated and a neutral control condition), but there was no clear relationship 
between the syllabic structure of the prime and the target.

The aim of the present study is twofold. First, we would like to know whether the syllable plays a role in the production of Dutch. Dutch is similar to English with respect to syllable structure. Based on the English results (Ferrand et al., 1997), one might expect a syllable priming effect for Dutch. Baumann's (1995) study, however, did not show such an effect. A possible reason why Baumann (1995) did not find a syllable priming effect in Dutch is that her interfering stimuli were not masked (Forster, 1987; Humphreys et al., 1987). Maybe small syllable match effects were overruled by strategic effects. Therefore, this study applies the masked priming paradigm to investigate the effect of syllable primes in four word naming experiments and one picture naming experiment with Dutch materials.

Second, the masked syllable priming paradigm might be used to find out more about the syllable affiliation of intervocalic consonants in Dutch, especially with respect to ambisyllabic consonants. Ambisyllabic consonants belong to two syllables at the same time (Booij, 1995), such as the intervocalic /p/ in kapper /ka[p]ər/ ('hairdresser'). Approximately $8 \%$ of all Dutch words (type frequency) include ambisyllabic consonants and hence ambiguous syllable boundaries. However, as opposed to English, ambisyllabic consonants are in general marked in the spelling by double consonants. Evidence from syllabification experiments shows that native speakers of Dutch generally affiliate ambisyllabic consonants with both the preceding and the following syllable (Schiller et al., 1997). Therefore, it might be hypothesized that $k a$ and kap both match the first syllable of the target kapper equally well and should thus yield similar priming effects for CV[C] targets (Ferrand et al., 1997).

All experiments used the masked priming paradigm. Naming can be facilitated when a target is immediately preceded by the brief exposure (usually between 20 and $60 \mathrm{~ms}$ ) of a visually masked prime that is orthographically and/or phonologically related to the target (Ferrand, Grainger, \& Segui, 1994; Forster \& Davis,
1991; Forster et al., 1987; Grainger \& Ferrand, 1996). Masking the primes has the advantage of minimizing the possibility of task-specific strategic effects (Ferrand et al., 1994; Forster, 1987, 1993; Forster \& Davis, 1991; Forster et al., 1987; Grainger \& Ferrand, 1996; Humphreys et al., 1987). Experiments 1, 3, 4, and 5 involved a word naming task and Experiment 2 a picture naming task. The main dependent variable was the naming latency, i.e., the interval between the onset of target presentation and speech onset. The first syllable of the targets had one of the following three $\mathrm{CV}$ structures: $\mathrm{CV}$, e.g., KANO /ka.no/ ('canoe') (CV targets hereafter); CVC, e.g., KAKTUS /kak.tus/ ('cactus') (CVC targets hereafter); or $\mathrm{CV}[\mathrm{C}]$, e.g., KAPPER /ka[p]ər/ ('hairdresser') (CV[C] targets hereafter). The materials were obtained from the CELEX (CEntre for LEXical information) lexical database (Baayen, Piepenbrock, \& Gulikers, 1995; Burnage, 1990). In each experiment, different kinds of primes were used. Related primes were identical to the beginning of a target followed by a number of hash marks (e.g., ka\#\#\#\# or kak\#\#\# for the target KAKTUS). In Experiment 5, percent signs instead of hash marks were used to follow the primes. Depending on the CV structure of the target, the prime either matched the first syllable of the target (syllable match condition) or it was shorter or longer than the target's first syllable (syllable mismatch condition). In addition, there was a neutral baseline condition (e.g., \%\&\$\#\#\#).

\section{EXPERIMENT 1: WORD NAMING WITH CV, CVC, AND CV[C] TARGETS}

In Experiment 1 the effect of $\mathrm{CV}$ and $\mathrm{CVC}$ primes on $\mathrm{CV}, \mathrm{CVC}$ and $\mathrm{CV}[\mathrm{C}]$ target words (e.g., KANO ('canoe'), KAKTUS ('cactus'), and KAPPER ('hairdresser'), respectively) was tested. CV and CVC targets had clear syllable boundaries, whereas the syllable structure was ambiguous in $\mathrm{CV}[\mathrm{C}]$ targets. If there is a syllable priming effect in Dutch, $\mathrm{CV}$ but not CVC primes should facilitate the naming of $\mathrm{CV}$ targets. Similarly CVC primes should yield facilitation for CVC targets, but there should be no effect from $\mathrm{CV}$ primes. On the basis of the 


\begin{tabular}{|c|c|c|c|c|}
\hline type of stimulus & $\begin{array}{c}\text { syllable } \\
\text { match } \\
\text { condition }\end{array}$ & $\begin{array}{l}\text { syllable } \\
\text { mismatch } \\
\text { condition }\end{array}$ & $\begin{array}{l}\text { neutral } \\
\text { control } \\
\text { condition }\end{array}$ & $\begin{array}{l}\text { exposure } \\
\text { duration }\end{array}$ \\
\hline forward mask & $\# \# \# \# \# \#$ & \#\#\#\#\#\# & \#\#\#\#\#\# & $500 \mathrm{~ms}$ \\
\hline prime & Ėl\#\#\# & モi\#\#\#\# & $8 \& \$ \# \# \#$ & $50 \mathrm{~ms}$ \\
\hline backward mask & \#\#\#\#\#\# & \#\#\#\#\#\# & \#\#\#\#\#\# & $17 \mathrm{~ms}$ \\
\hline target & FILTER & FILTER & FILTER & $\max 2000 \mathrm{~ms}$ \\
\hline
\end{tabular}

FIG. 1. Sequencing of the stimuli in the masked priming paradigm used in the experiments of this study. (In Experiment 2 the target word was replaced by a target picture, and in Experiment 5 the prime stimuli were followed by percent signs.

results obtained by Ferrand et al. (1997) for ambisyllabic target words in English, both CV and CVC primes should facilitate the naming of $\mathrm{CV}[\mathrm{C}]$ targets, but there should be no significant difference between these two priming condition.

\section{Method}

Participants. Eighteen participants from the pool of participants of the Max Planck Institute for Psycholinguistics in Nijmegen took part in Experiment 1 in exchange for pay. All participants were native speakers of Dutch and had normal or corrected-to-normal vision.

Procedure. Participants were tested individually. They sat in front of a computer screen in a sound-proof darkened room. The computer screen was a Samtron SC-428 TXL with a refresh rate of $60 \mathrm{~Hz}$; i.e., the interval to build up a whole frame on the screen was $16.7 \mathrm{~ms}$. The four-field masking procedure used here was adopted from Ferrand et al. (1996, 1997). Each trial sequence began with a forward mask followed by a prime, a backward pattern mask, and the target (see Figure 1).

The four visual stimuli were presented in rapid succession, each stimulus being superimposed on the previous one. The forward pattern mask consisted of a row of hash marks (e.g.,
\#\#\#\#\#), which appeared for $500 \mathrm{~ms}$ on the screen. The number of hash marks was equal to the number of letters of the target word. Then the prime was presented in lower-case letters for $50 \mathrm{~ms}$. The length of the primes was identical to the length of the target words. In Experiment 2, picture targets were used and the length of the primes was equal to the length of the masks, i.e., six characters. After the presentation of the prime, the row of hash marks appeared again for $17 \mathrm{~ms}$. Then the target was presented and remained on the screen until a response was given. When no response was given within $2000 \mathrm{~ms}$, the target disappeared. Word targets were displayed in upper-case letters (e.g., KAKTUS) to reduce the visual overlap between prime and target. Masks, primes, and targets were presented in a nonproportional font (i.e., Courier). All items appeared in the center of the screen as white characters on black background. Each upper-case character of the target word covered approximately $0.40^{\circ}$ of the visual angle from the viewing distance of $100 \mathrm{~cm}$. Target words were between four and seven letters in length, subtending between $1.6^{\circ}$ and $2.8^{\circ}$ of the visual angle. Participants were instructed to fixate the hash marks at the beginning of a trial sequence and to name the target as fast and as accurately as they could. Participants were not informed about the presence of the prime. Naming latencies were measured by means of a voice key (Sennheiser ME 40 microphone), which was activated at the onset of target presentation. One second after the voice key was triggered, the next trial sequence started. The presentation of the trial sequences was controlled by NESU (Nijmegen Experimental Setup). Responses were recorded on DAT for subsequent evaluation of the voice key measurements. A response was considered an error when it exceeded the timeout of $2000 \mathrm{~ms}$, when it included a disfluency, when a wrong name was produced, or when the voice key was triggered incorrectly. Incorrect responses were excluded from the reaction time analyses.

After the completion of each experiment, post hoc tests of prime visibility were conducted to assess the amount of perceptual awareness of the primes. In an adapted version of the prime 


\section{TABLE 1}

Percentage of Correct Responses (PC) with Standard Errors (SE) in the Prime Visibility Tests Used in the Five Experiments

\begin{tabular}{cllr}
\hline Experiment & Test type & PC & SE \\
\hline & & & \\
2 & four-choice & 28.27 & 7.67 \\
3 & four-choice & 29.73 & 5.68 \\
4 & 2 AFC & 65.82 & 16.86 \\
5 & four-choice & 28.19 & 5.88 \\
& four-choice & 25.77 & 6.86 \\
\hline
\end{tabular}

visibility test used by Brown and Hagoort (1993), participants carried out a forced-choice recognition task. Syllable primes were presented under the same masking conditions as in the naming experiments, but instead of a word or a picture target the backward pattern mask was immediately followed by four different strings which appeared separated by two blanks in a row in the center of the screen. One of the four strings was identical to the syllable prime; the other were foils. In Experiments 1, 2, 4, and 5 , participants were asked to identify and name the syllable prime from the set of these four strings. In Experiment 3, participants carried out a two-alternatives forced choice (2AFC) test, in which they had to decide on the identity or non-identity of the prime and target. The results from the visibility tests are summarized in Table 1. The fact that participants performed practically at chance level (except for in Experiment 3$)^{2}$ in the tests of prime visibility reflects participants' subjective reports that they were generally unaware of the presence of the primes.

Materials. The entire set of target words consisted of 54 monomorphemic bisyllabic Dutch nouns (see Appendix A), 18 in each of the three target categories, i.e., $\mathrm{CV}, \mathrm{CVC}$, and $\mathrm{CV}[\mathrm{C}]$

\footnotetext{
${ }^{2}$ In a post hoc analysis for Experiment 3 the data from those 16 participants who performed at an accuracy rate above $70 \%$ correct responses were eliminated. For the remaining group of 20 participants the same pattern of results was obtained as for the entire group of participants, except that the $7 \mathrm{~ms}$ difference between the $\mathrm{CV}$ and the CVC priming conditions no longer reached significance (means: neutral prime $=549 \mathrm{~ms}, \mathrm{CV}$ prime $=534 \mathrm{~ms}, \mathrm{CVC}$ prime $=527$ ).
}

words. The mean frequency of occurrence per one million word forms was 16.3 for the CV targets, 17.1 for the CVC targets, and 6.0 for the $\mathrm{CV}[\mathrm{C}]$ targets as determined by CELEX.

There were two types of related primes corresponding either to the first two letters (CV primes) or to the first three letters of a target word (CVC primes). In addition, there was a neutral control prime consisting of the three characters \%\&\$. To give an example, in the syllable match condition the CVC target KAKTUS was preceded by a CVC prime (e.g., kak\#\#\#-KAKTUS), in the syllable mismatch condition by a CV prime (e.g., ka\#\#\#\#-KAKTUS), and in the control condition by a neutral prime (e.g., \%\&\$\#\#-KAKTUS).

Design. Experiment 1 had a within-participants design. Participants received two practice and three test blocks. In a practice block each target word was presented once, preceded by a fixation cross. In a test block each target appeared once in each of the three priming conditions. Items were randomized individually for each participant within blocks. There was a self-paced pause between each block.

\section{Results}

Naming latencies shorter than $300 \mathrm{~ms}$ and longer than $1000 \mathrm{~ms}$ were counted as errors (less than $1 \%$ of the data). The mean naming latencies and error rates are summarized in Table 2. Analyses of variance were run with Target Structure $(\mathrm{CV}, \mathrm{CVC}$, or $\mathrm{CV}[\mathrm{C}])$, Prime Structure (CV, CVC, or neutral), and Block (1, 2 , or 3$)$ as independent variables. Separate analyses were carried out with participants $\left(F_{1}\right)$ and items $\left(F_{2}\right)$ as random variables. As a general rule, only results that were significant by participants and items $(p<0.5)$ will be reported.

Error rates. There were $1.59 \%$ errors altogether. None of the main effects or interactions were significant.

Reaction times. Neither the main effects of Block and Target Structure nor any of the interactions involving these variables were significant. The only main effect that was significant was the effect of Prime Structure $\left(F_{1}(2,34)=\right.$ 93.93, $M S_{\mathrm{e}}=222.77, p<.001 ; F_{2}(2,102)=$ $\left.215.16, M S_{\mathrm{e}}=97.61, p<.001\right)$. Target names 
TABLE 2

Mean Naming Latencies (in ms) and Percentage of Errors (in Parentheses) in Experiment 1

\begin{tabular}{lcccc}
\hline & \multicolumn{3}{c}{ Target structure } \\
\cline { 2 - 4 } Prime structure & $\begin{array}{c}\text { CV words } \\
\text { (e.g., KANO) }\end{array}$ & $\begin{array}{c}\text { CVC words } \\
\text { (e.g., KAKTUS) }\end{array}$ & $\begin{array}{c}\text { CV[C] words } \\
\text { (e.g., KAPPER) }\end{array}$ & Mean \\
\hline CV primes & $455(1.6)$ & $461(1.2)$ & $461(1.1)$ & 459 \\
CVC primes & $448(1.2)$ & $453(1.5)$ & $449(1.3)$ & 450 \\
Neutral primes & $487(2.4)$ & $492(2.4)$ & $484(1.4)$ & 488 \\
\hline
\end{tabular}

were produced fastest when preceded by a CVC prime, slower when preceded by a CV prime, and slowest when preceded by a neutral prime. Dunnett's tests $(p<.05)$ showed that both the $\mathrm{CV}$ and the CVC priming condition differed significantly from the neutral control condition. Planned comparisons showed that the $9 \mathrm{~ms}$ difference between the $\mathrm{CV}$ and the CVC priming conditions was also significant $\left(t_{1}(34)=3.26\right.$, $M S_{\mathrm{e}}=74.26, p<.01 ; t_{2}(106)=4.89, M S_{\mathrm{e}}=$ 98.28, $p<.01)$.

\section{Discussion}

The data did not show any sign of a syllable match effect. Both CV and CVC primes significantly facilitated the naming of the targets. CVC primes yielded larger facilitation effects than $\mathrm{CV}$ primes for all three categories of target items. Thus, the size of the priming effect increased with increasing segmental overlap between prime and target. This result contradicts the syllable priming hypothesis according to which priming should only occur in the syllable match condition. The naming latencies for the $\mathrm{CV}[\mathrm{C}]$ targets showed a $12 \mathrm{~ms}$ difference between the $\mathrm{CV}$ and the CVC priming conditions (461 $\mathrm{ms}$ and $449 \mathrm{~ms}$, respectively), which proved to be significant $\left(t_{1}(34)=3.72, M S_{\mathrm{e}}=\right.$ 98.96, $p<.01 ; t_{2}(102)=3.74, M S_{\mathrm{e}}=97.61$, $p<.01)$. This latter result also stands in contradiction to the syllable priming hypothesis which predicted no difference between $\mathrm{CV}$ and CVC primes for CV[C] targets.

The results clearly call for an alternative account. It is hypothesized here that the obtained facilitation effects are due to the segmental overlap between prime and target, and that the size of the priming effect is dependent on the amount of overlap but independent of the correspondence of the syllabic structure of prime and target. Since the magnitude of the priming effects in Experiment 1 increased with the increase in overlap between prime and target, the results are perfectly in accordance with a segmental overlap hypothesis. Experiment 2 was designed to test the same materials as in Experiment 1 using a different task, i.e., picture naming.

\section{EXPERIMENT 2: PICTURE NAMING WITH CV, CVC, AND CV[C] TARGETS}

Word naming does not necessarily involve all stages of the speech production process because printed words can be named by means of nonlexical grapheme-to-phoneme conversion rules, i.e., without accessing the whole-word representation of the target in the mental lexicon (Bajo, 1988). In contrast, picture naming presumably involves lexical access because the retrieval of a picture's name must be preceded by the activation of the concept and the lemma in order to access semantic information (Huttenlocher \& Kubicek, 1983; see Glaser, 1992 for a review). Therefore, picture naming can be considered as a task involving all stages of speech production. Another reason to carry out a picture naming experiment was to exclude the possibility that the priming effects obtained in the word naming task (Experiment 1) were partly due to the visual similarity between prime and target. Although prime and target were separated by a pattern mask and appeared in different cases, pure visual overlap effects between prime and target are still possible in word nam- 
ing (Davis \& Forster, 1994; Forster \& Davis, 1984), whereas they cannot occur in a picture naming experiment.

The picture naming task has been shown to be sensitive to form priming effects before. Ferrand et al. (1994) showed that the naming of a picture in French (e.g., pied) was facilitated when preceded by the masked printed picture name (identity priming) (e.g., PIED) or a pseudohomophone of its name (e.g., PIEZ), but not when preceded by a masked orthographically related nonhomophonic prime (e.g., PIEN). In a more recent study, Ferrand et al. (1996) showed that picture naming, just as word naming, was facilitated by the prior masked presentation of the picture name's first syllable as compared to a condition in which the prime was either shorter or longer than the first syllable. However, Ferrand et al. (1997) did not include a picture naming experiment in their syllable priming study with English materials.

The aim of Experiment 2 is to test whether form priming effects in the picture naming task can be found with Dutch materials and, if so, whether the results are in accordance with the syllable priming hypothesis or rather with the segmental overlap hypothesis introduced above.

\section{Method}

Participants. Eighteen participants drawn from the same pool as described for Experiment 1 took part in Experiment 2.

Procedure. The procedure was the same as in Experiment 1 except that the targets were pictures. Participants first received each picture once on the computer screen to learn the "appropriate" picture names. Each picture appeared on the screen and after two seconds the "appropriate" name was added below the picture. Both remained in view for another three seconds. Participants were asked to learn the "appropriate'" name for each picture. Following this learning phase, participants received two practice and three test blocks.

Materials. Primes and targets were the same as in Experiment 1, but instead of printed words, line drawings were presented as targets. The target words used in Experiment 1 had been chosen such that all targets corresponded to pictorial objects. Altogether, there were 54 white-on-black line drawings of common objects, 18 for each of the three target categories, i.e., CV, CVC, and CV[C] words (see Appendix A). The pictures were drawn using Aldus Freehand 3.1, converted to Adobe Illustrator 3.2, and saved in AI format. For the presentation by means of NESU the drawings were then converted to PCX format.

The target pictures had been selected on the basis of the results obtained from two pretests. The aim of the first pretest was to determine the dominant naming responses to a set of pictures. 20 participants received printed line drawings of 91 objects and were asked to write down their names. The second pretest was designed to determine the mean response latencies for those pictures that were most consistently named in the first pretest. Another 20 participants first saw pictures of 71 objects on a computer screen. In a preview, pictures appeared individually on the screen and after two seconds the predominant picture name was added below each picture. Picture and picture name remained on the screen for another three seconds. Participants were asked to learn the association between the picture and its name. After this learning phase, only the pictures appeared on the screen again in randomized order, preceded by a fixation cross. Participants were asked to name each picture as fast as possible. Response latencies were measured by a voice key. Incorrect naming response were excluded from the reaction time analyses. As can be seen in Table 3, the 54 picture stimuli that were selected on the basis of the two pretests are closely matched with respect to mean frequency of occurrence, mean proportion of correct naming responses in spontaneous naming, and mean naming latencies.

Design. The design was the same as in Experiment 1 .

\section{Results}

Naming latencies shorter than $350 \mathrm{~ms}$ and longer than $1500 \mathrm{~ms}$ were counted as errors (less than $1 \%$ of the data). The mean naming latencies and error rates are summarized in Table 4. Analyses of variance were run with Target Structure $(\mathrm{CV}, \mathrm{CVC}$, or $\mathrm{CV}[\mathrm{C}])$, Prime 
TABLE 3

Mean Frequency of Occurrence, Mean Proportion of Correct Naming Responses, and Mean Naming Latencies of the Selected Picture Stimuli used in Experiment 2

\begin{tabular}{|c|c|c|c|}
\hline $\begin{array}{c}\text { Target } \\
\text { structure }\end{array}$ & $\begin{array}{l}\text { Mean frequency of } \\
\text { occurrence per one million } \\
\text { word forms (CELEX) }\end{array}$ & $\begin{array}{l}\text { Mean proportion of } \\
\text { correct responses } \\
\text { (pretest } 1)\end{array}$ & $\begin{array}{l}\text { Mean naming latencies } \\
\text { (pretest 2) }\end{array}$ \\
\hline $\mathrm{CV}$ targets & 16.3 & $70 \%$ & $806 \mathrm{~ms}(\mathrm{SD}=194 \mathrm{~ms})$ \\
\hline CVC targets & 17.1 & $72 \%$ & $861 \mathrm{~ms}(\mathrm{SD}=238 \mathrm{~ms})$ \\
\hline $\mathrm{CV}[\mathrm{C}]$ targets & 6.0 & $78 \%$ & $839 \mathrm{~ms}(\mathrm{SD}=234 \mathrm{~ms})$ \\
\hline
\end{tabular}

Structure (CV, CVC, or neutral), and Block (1, 2 , or 3) as independent variables.

Error rates. There were $2.87 \%$ errors altogether. None of the main effects or interactions were significant.

Reaction times. The main effect of Block was significant $\left(F_{1}(2,34)=5.34, M S_{\mathrm{e}}=3051.26\right.$, $p=.01 ; F_{2}(2,102)=20.87, M S_{\mathrm{e}}=787.72, p<$ $.001)$. Target pictures were named more slowly in block 1 (683 ms) than in block 2 (666 ms) and block 3 (666 ms). However, none of the interactions involving the variable Block approached significance. Therefore, the data were collapsed across blocks for the subsequent analyses.

The main effect of Target Structure was only significant by participants but not by items $\left(F_{1}(2,34)=24.12, M S_{\mathrm{e}}=428.20, p<.001\right.$; $F_{2}(2,51)=2.16$, n.s.). Participants named CV targets $(659 \mathrm{~ms})$ faster than $\mathrm{CV}[\mathrm{C}]$ targets $(669$ $\mathrm{ms}$ ) and CVC targets (687 ms). However, Target Structure did not interact with Prime Structure $\left(F_{1}(4,68)<1 ; F_{2}(4,102)<1\right)$.

Most importantly, the main effect of Prime Structure was significant $\left(F_{1}(2,34)=24.78\right.$,
$M S_{\mathrm{e}}=1523.98, p<.001 ; F_{2}(2,102)=76.86$, $\left.M S_{\mathrm{e}}=491.55, p<.001\right)$. Target pictures were named fastest when preceded by a CVC prime, slower when preceded by a CV prime, and slowest when preceded by a neutral prime. Dunnett's tests $(p<.05)$ showed that both the CV and the CVC priming conditions differed significantly from the neutral control condition. Planned comparisons showed that the $21 \mathrm{~ms}$ difference between the CV and the CVC priming conditions was also significant $\left(t_{1}(34)=\right.$ $2.47, M S_{\mathrm{e}}=507.38, p<.05 ; t_{2}(106)=4.44$, $\left.M S_{\mathrm{e}}=482.74, p<.01\right)$.

\section{Discussion}

The pattern of results is similar to the outcome of Experiment 1; i.e., there was no sign of a syllable match effect. Both CVC and CV primes yielded facilitatory effects for all three categories of target items. Furthermore, CVC primes yielded stronger facilitation effects than $\mathrm{CV}$ primes showing that the size of the priming effect increased with an increase in segmental overlap between prime and target. The naming latencies for the CV[C] targets showed a differ-

TABLE 4

Mean Naming Latencies (in ms) and Percentage of Errors (in Parentheses) in Experiment 2

\begin{tabular}{|c|c|c|c|c|}
\hline \multirow[b]{2}{*}{ Prime structure } & \multicolumn{3}{|c|}{ Target structure } & \multirow[b]{2}{*}{ Mean } \\
\hline & $\begin{array}{l}\text { CV pictures } \\
\text { (e.g., kano) }\end{array}$ & $\begin{array}{c}\text { CVC pictures } \\
\text { (e.g., kaktus) }\end{array}$ & $\begin{array}{c}\mathrm{CV}[\mathrm{C}] \text { pictures } \\
\text { (e.g., kapper) }\end{array}$ & \\
\hline $\mathrm{CV}$ primes & $655(2.9)$ & $681(2.6)$ & $663(2.4)$ & 667 \\
\hline CVC primes & $631(2.9)$ & $666(3.1)$ & $648(2.5)$ & 648 \\
\hline Neutral primes & $691(3.4)$ & $713(3.5)$ & $697(3.0)$ & 700 \\
\hline
\end{tabular}


ence of $15 \mathrm{~ms}$ between the $\mathrm{CV}$ and the CVC priming conditions (663 ms and $648 \mathrm{~ms}$, respectively), which was again significant $\left(t_{1}(34)=\right.$ $2.04, M S_{\mathrm{e}}=548.90, p<.05 ; t_{2}(102)=2.22$, $\left.\mathrm{MS}_{\mathrm{e}}=491.55, p<.05\right)$. These results contradict the syllable priming hypothesis, but they support the segmental overlap hypothesis.

Although the results of Experiment 1 and 2 both support the segmental overlap hypothesis, they have one potential shortcoming with respect to the materials that were used. Due to other constraints on the materials (e.g., all depicted objects had to correspond to a bisyllabic, monomorphemic Dutch noun with a precisely defined phonological structure such that each itme belonged to one target category), it was not possible to find triplets that shared the first three letters. Although such triplets exist in Dutch (e.g., fakir, faktor, and fakkel), they generally contain targets that do not correspond to pictorial objects (e.g., faktor). This has the potential disadvantage that targets from different categories were not preceded by the same primes. Therefore, one might argue that $\mathrm{CV}, \mathrm{CVC}$, and $\mathrm{CV}[\mathrm{C}]$ targets are not comparable. Furthermore, using different primes for each target may induce additional variance in the data. Experiments 3, 4, and 5 were designed to replicate the obtained segmental overlap effects with better controlled materials using the word naming task.

\section{EXPERIMENT 3: WORD NAMING WITH CVC AND CV[C] TARGETS}

In Experiment 3 the effect of $\mathrm{CV}$ and $\mathrm{CVC}$ primes (e.g., fa and fak) on CVC and CV[C] target words (e.g., FAKTOR and FAKKEL) was tested. CVC targets had a clear syllable boundary, whereas the syllable structure was ambiguous in $\mathrm{CV}[\mathrm{C}]$ targets. The segmental overlap hypothesis predicts that both $\mathrm{CV}$ and CVC primes should facilitate the naming of $\mathrm{CVC}$ and $\mathrm{CV}[\mathrm{C}]$ targets and that the priming effects should be larger in the CVC than in the $\mathrm{CV}$ priming condition for both types of targets.

\section{Method}

Participants. Thirty-six participants drawn from the same pool as described for Experiment
1 took part in Experiment 3. There were three groups, each comprising 12 participants.

Procedure. The procedure was the same as in Experiment 1.

Materials. The entire set of target words consisted of 84 monomorphemic bisyllabic Dutch nouns (see Appendix B). Targets could be grouped into two different subsets. Set A consisted of $21 \mathrm{CVC}$ words (e.g., FAKTOR) and 21 $\mathrm{CV}[\mathrm{C}]$ words (e.g., FAKKEL). The mean frequency of occurrence per one million word forms was 4.9 for the CVC and 6.6 for the $\mathrm{CV}[\mathrm{C}]$ items of Set $\mathrm{A}$ as determined by CELEX. Items of Set A were grouped into pairs such that the first three letters of both members of a pair were identical (e.g., FAK). Set B also contained $21 \mathrm{CVC}$ words and $21 \mathrm{CV}[\mathrm{C}]$ words (e.g., BINDER and BOBBEL, respectively). The mean frequency of occurrence per one million word forms was 8.3 for the CVC and 9.3 for the CV[C] items of Set B as determined by CELEX. However, items of Set B could not be grouped into pairs in the same way as items of Set A although an effort was made to maximize their segmental overlap.

There were two types of related primes corresponding either to the first two letters of a target word (CV primes) or to the first three letters of a target word (CVC primes). In the case of the Set A items, the two related primes were identical for the two members of a pair (e.g., fa and fak for FAKTOR and FAKKEL). For the Set B items, related primes were different for CVC and CV[C] words (e.g., bi and bin for BINDER vs bo and bob for BOBBEL). Neutral primes consisted of the three characters \%\&\$.

Design. Experiment 3 had a between-participants design. For each target word there were three prime-target pairs, namely, CV primetarget (e.g., fa\#\#\#\#-FAKTOR), CVC prime-target (e.g., fak\#\#\#-FAKTOR), and neutral primetarget (e.g., \%\&\$\#\#-FAKTOR). Prime-target pairs were rotated across three groups of participants such that each participant saw each target word only once, but still received all three experimental conditions. Each participant saw 84 prime-target pairs, 28 in each condition. The 84 prime-target pairs were grouped into four 
TABLE 5

Mean Naming Latencies (in ms) and Percentage of Errors (in Parentheses) in Experiment 3

\begin{tabular}{|c|c|c|c|c|}
\hline \multirow[b]{2}{*}{ Item type } & \multirow[b]{2}{*}{ Prime structure } & \multicolumn{2}{|c|}{ Target structure } & \multirow[b]{2}{*}{ Mean } \\
\hline & & $\begin{array}{c}\text { CV[C] words } \\
\text { (e.g., FAKKEL) }\end{array}$ & $\begin{array}{c}\text { CVC words } \\
\text { (e.g., FAKTOR) }\end{array}$ & \\
\hline \multirow[t]{4}{*}{ Set A } & CV primes (e.g., fa\#\#\#\#) & $526(2.8)$ & $535(2.4)$ & 529 \\
\hline & CVC primes (e.g., fak\#\#\#) & $516(3.2)$ & $525(2.4)$ & 520 \\
\hline & Neutral primes (e.g., \%\&\$\#\#) & $542(3.2)$ & $545(2.0)$ & 542 \\
\hline & & $\begin{array}{c}\mathrm{CV}[\mathrm{C}] \text { words } \\
\text { (e.g., BAKKER) }\end{array}$ & $\begin{array}{l}\text { CVC words } \\
\text { (e.g., BANJO) }\end{array}$ & Mean \\
\hline \multirow[t]{3}{*}{ Set B } & CV primes (e.g., ba\#\#\#\# or ba\#\#\#) & $515(3.6)$ & $521(0.4)$ & 518 \\
\hline & CVC primes (e.g., bak\#\#\# or ban\#\#) & $509(3.2)$ & $512(1.6)$ & 510 \\
\hline & Neutral primes (e.g., \%\&\$\#\#\# or \%\&\$\#\#) & $534(1.6)$ & $533(2.8)$ & 533 \\
\hline
\end{tabular}

blocks each containing 21 prime-target pairs. The order of presentation of the four blocks was counterbalanced across participants in each group. Prime-target pairs were randomized individually for each participant within each block.

\section{Results}

Naming latencies shorter than $300 \mathrm{~ms}$ and longer than $1000 \mathrm{~ms}$ were counted as errors (less than $1 \%$ of the data). The mean naming latencies and error rates are summarized in Table 5. Analyses of variance were run with Item Type (Set A or Set B), Target Structure (CVC or CV[C]), Prime Structure (CV, CVC, or neutral), and Group $(1,2$, or 3$)$ as independent variables.

Error rates. There were $2.51 \%$ errors altogether. None of the main effects or interactions were significant.

Reaction times. None of the main effects of Item Type, Group, and Target Structure nor any of the interactions involving these variables were significant. Therefore, items of Set A and B were analyzed together. Similarly, data from the three groups were collapsed for the subsequent analyses.

Importantly, the main effect of Prime Structure was significant $\left(F_{1}(2,70)=22.36, M S_{\mathrm{e}}=\right.$ $388.37, p<.001 ; F_{2}(2,164)=18.80, M S_{\mathrm{e}}=$ $523.79, p<.001)$. The naming latencies were shortest when targets were preceded by a CVC prime $(516 \mathrm{~ms})$, slightly longer when preceded by a CV prime (524 ms), and longest when preceded by a neutral prime (538 ms). Dunnett's tests $(p<.05)$ showed that both the CV and the CVC priming condition differed significantly from the neutral control condition. Planned comparisons showed that the $8 \mathrm{~ms}$ difference between the $\mathrm{CV}$ and the CVC priming condition was also significant $\left(t_{1}(70)=2.32\right.$, $M S_{\mathrm{e}}=192.91, p<.05 ; t_{2}(166)=2.07, M S_{\mathrm{e}}=$ 519.46, $p<.05)$.

\section{Discussion}

Both the naming latencies for $\mathrm{CVC}$ and $\mathrm{CV}[\mathrm{C}]$ target words were shortened significantly when preceded by a $\mathrm{CV}$ or a $\mathrm{CVC}$ prime as compared to a neutral control condition. CVC primes yielded significantly larger priming effects than $\mathrm{CV}$ primes for both types of target words. Again, this result supports the segmental overlap hypothesis, whereas it stands in contradiction to the syllable priming hypothesis according to which the naming of CVC targets should only be facilitated when preceded by a CVC prime but not when preceded by a CV prime. However, CV primes also yielded a significant facilitation effect for these targets. The naming latencies of $\mathrm{CV}[\mathrm{C}]$ targets was facilitated by both $\mathrm{CV}$ and CVC primes, but the $8 \mathrm{~ms}$ difference between the two priming conditions 
did not reach significance. However, as can be seen in Table 5, it was again the CVC priming condition that yielded the largest facilitation effects. The fact that the interaction between Item Type and Prime Structure did not approach significance showed that there was no difference between the priming effects for CVC and $\mathrm{CV}[\mathrm{C}]$ targets that shared their initial segments and those that did not.

\section{EXPERIMENT 4: WORD NAMING WITH CV AND CVC TARGETS}

Experiment 4 tested the effect of $\mathrm{CV}$ and CVC primes (e.g., de and del) on CV and CVC target words (e.g., DELER and DELTA), both having unambiguous syllabification. The segmental overlap hypothesis predicts that both $\mathrm{CV}$ and CVC primes should yield a facilitation effect for both types of target words, no matter whether prime and target share the first syllable or not. Effects should be larger for CVC than for $\mathrm{CV}$ primes due to greater segmental overlap with the target.

\section{Method}

Participants. Twenty-four participants drawn from the same pool as described for Experiment 1 took part in Experiment 4.

Procedure. The procedure was exactly the same as in Experiment 1.

Materials. There were 84 target words (see Appendix C). All target words were monomorphemic bisyllabic Dutch nouns. Again, there were two different subsets of target words. Set A consisted of $21 \mathrm{CVC}$ words beginning with a CVC syllable (e.g., FAKTOR) and $21 \mathrm{CV}$ words beginning with a CV syllable (e.g., FAKIR). The mean frequency of occurrence per one million word forms was 6.2 for the CVC and for the $\mathrm{CV}$ items of Set $\mathrm{A}$ as determined by CELEX. Items of Set A were grouped into pairs such that the first three letters of both members of a pair were identical (e.g., FAK). Set B also contained $21 \mathrm{CVC}$ words (e.g., PANTER) and $21 \mathrm{CV}$ words (e.g., POKER), but they could not be grouped into pairs in the same way as items of Set A. The mean frequency of occurrence per one million word forms was 9.3 for the CVC and 32.7 for the CV items of Set B as determined by CELEX.

There were two types of related primes, CV and CVC primes. For Set A items, the two related primes were identical for the two members of a pair (e.g., fa and fak for FAKTOR and FAKIR). For Set B items, related primes were different for CVC and CV target words (e.g., pa and pan for PANTER vs po and pok for POKER). Neutral primes consisted of the three characters \%\&\$.

Design. Experiment 4 had a within-participants design. Participants received each target three times, once preceded by a CV prime (e.g., fa\#\#\#\#-FAKTOR), once preceded by a CVC prime (e.g., fak\#\#\#-FAKTOR), and once preceded by a neutral prime (e.g., \%\&\$\#\#-FAKTOR). The 252 prime-target pairs were grouped into three different blocks such that half of the targets in each block came from Set A and half came from Set B. Half of the items from Set A and $\mathrm{B}$ were $\mathrm{CV}$ targets, the other half were CVC targets. Furthermore, the number of priming conditions was equally distributed among the Set A and B items within each block. Each participant received all three blocks, but the order of blocks was counterbalanced across participants. Items were randomized individually for each participant within blocks.

\section{Results}

Naming latencies shorter than $300 \mathrm{~ms}$ and longer $1000 \mathrm{~ms}$ were counted as errors (less than $1 \%$ of the data). The mean naming latencies and error rates are summarized in Table 6. Analyses of variance were run with Item Type (Set A or Set B), Target Structure (CV or CVC), Prime Structure (CV, CVC, or neutral), and Block $(1,2$, or 3$)$ as independent variables.

Error rates. There were $2.46 \%$ errors altogether. None of the main effects or interactions were significant.

Reaction times. The main effect of Block was significant $\left(F_{1}(2,46)=37.71, M S_{\mathrm{e}}=1235.42\right.$, $p<.001 ; F_{2}(2,164)=160.06, M S_{\mathrm{e}}=522.58$, $p<.001)$, reflecting the fact that naming latencies decreased with repetition. Target words were named slowest at the first presentation (517 ms), faster at the second presentation (491 
TABLE 6

Mean Naming Latencies (in ms) and Percentage of Errors (in Parentheses) in Experiment 4

\begin{tabular}{|c|c|c|c|c|}
\hline \multirow[b]{2}{*}{ Item type } & \multirow[b]{2}{*}{ Prime structure } & \multicolumn{2}{|c|}{ Target structure } & \multirow[b]{2}{*}{ Mean } \\
\hline & & $\begin{array}{c}\text { CV words } \\
\text { (e.g., DELER) }\end{array}$ & $\begin{array}{l}\text { CVC words } \\
\text { (e.g., DELTA) }\end{array}$ & \\
\hline \multirow[t]{4}{*}{ Set A } & CV primes (e.g., de\#\#\#) & $485(4.0)$ & $497(2.6)$ & 491 \\
\hline & CVC primes (e.g., del\#\#) & $483(4.6)$ & $487(1.8)$ & 485 \\
\hline & Neutral primes (e.g., \%\&\$\#) & $513(4.0)$ & $515(2.0)$ & 514 \\
\hline & & $\begin{array}{c}\text { CV words } \\
\text { (e.g., POKER) }\end{array}$ & $\begin{array}{l}\text { CVC words } \\
\text { (e.g., PANTER) }\end{array}$ & Mean \\
\hline \multirow[t]{3}{*}{ Set B } & CV primes (e.g., po\#\#\# or pa\#\#\#) & $490(1.4)$ & $501(1.2)$ & 495 \\
\hline & CVC primes (e.g., pok\#\# or pan\#\#\#) & $480(2.6)$ & 491 (1.6) & 485 \\
\hline & Neutral primes (e.g., $\% \& \$ \# \#$ or $\% \& \$ \# \# \#)$ & $505(2.6)$ & $513(1.6)$ & 509 \\
\hline
\end{tabular}

$\mathrm{ms}$ ), and fastest at the third presentation (482 $\mathrm{ms})$. The interaction between Block and Target Structure was not significant $\left(F_{1}(2,46)=1.15\right.$, n.s.; $\left.F_{2}(2,164)<1\right)$, but the interaction between Block and Prime Structure was significant $\left(F_{1}(4,92)=3.03, M S_{\mathrm{e}}=308.63, p=.022\right.$; $\left.F_{2}(4,328)=2.62, M S_{\mathrm{e}}=689.61, p=.035\right)$. This interaction reflects the fact that the priming effects increased across blocks. However, the three-way interaction between Block, Target Structure, and Prime Structure did not approach significance $\left(F_{1}(4,92)=1.86\right.$, n.s.; $F_{2}(4,328)<$ $1)$. Thus, with repeated production of the target words, the pattern of the priming effect remained the same. Therefore, the data were collapsed across blocks in the subsequent analyses.

Neither the main effects of Target Structure and Item Type nor any of the interactions involving these variables were significant. Therefore, items of Set A and B were analyzed together.

Most importantly, the main effect of Prime Structure was significant $\left(F_{1}(2,46)=96.60\right.$, $M S_{\mathrm{e}}=90.71, p<.001 ; F_{2}(2,146)=114.05$, $\left.M S_{\mathrm{e}}=135.96, p<.001\right)$. Naming latencies were shortest when targets were preceded by CVC primes (485 ms), slightly longer when preceded by CV primes (493 ms), and longest when preceded by neutral primes (512 ms). Dunnett's tests $(p<.05)$ showed that both the $\mathrm{CV}$ and the CVC priming condition differed significantly from the neutral control condition. Planned comparisons showed that the $8 \mathrm{~ms}$ difference between the $\mathrm{CV}$ and the CVC priming conditions was also significant $\left(t_{1}(46)=4.12\right.$, $M S_{\mathrm{e}}=45.20, p<.01 ; t_{2}(166)=4.44, M S_{\mathrm{e}}=$ $137.35, p<.01)$.

\section{Discussion}

The results of Experiment 4 clearly support the segmental overlap hypothesis. Both $\mathrm{CV}$ and CVC primes yielded significant priming effects for $\mathrm{CV}$ and $\mathrm{CVC}$ targets when compared to the neutral control condition. Furthermore, it was predicted that the greater the overlap between prime and target, the greater the facilitation effect obtained by the prime. This prediction was also confirmed. Thus, the segmental overlap hypothesis can account for the outcome of Experiment 4 without making reference to the syllabic structure of prime and target.

\section{EXPERIMENT 5: WORD NAMING WITH CV AND CVC TARGETS}

The previous experiments support the segmental overlap hypothesis but not the syllable priming hypothesis. However, in Experiments 1 and 4 the syllabic structure and the length of the target words were confounded, in that CV targets were generally shorter than CVC targets. Because the forward mask always matched the target in length (e.g., \#\#\#\# for KANO and 
\#\#\#\#\#\# for KAKTUS), participants may have inferred the syllabic structure of the target from the forward mask. Therefore, primes (e.g., ka\#\# or kan\# for KANO and ka\#\#\#\# or kak\#\#\# for KAKTUS) may not have provided any additional information about the syllabic structure of the target. This may have been the reason that no syllabic effects were obtained.

Furthermore, in Experiments 1 to 4 hash marks were used both as masks and to follow the prime stimuli. This may have encouraged participants to engage in a strategy that distracted them from the primary task of the experiments. Maybe they concentrated only on the beginning of the prime and tried to match the prime with the target. The more segments were shared by prime and target, the more priming was obtained independently of the syllabic structure of prime and target. This strategy may have been another reason why segmental effects instead of syllabic overlap effects were obtained.

Experiment 5 was carried out to control for these potential confounds. All target words used in Experiment 5 had the same length in segments but differed in syllable structure. Also, the hash marks after the prime stimuli were replaced with percent signs following the procedure used by Ferrand et al. (1996, 1997). Experiment 5 tested the strong prediction made by the segmental overlap hypothesis that priming effects should increase with an increased segmental overlap between prime and target. Priming effects should increase from $\mathrm{k} \% \% \% \% \%$ to $\mathrm{ka} \% \% \% \%$, kak $\% \% \%$, kakt $\% \%$, kaktu\%, and should be greatest for repetition priming, e.g., kaktus, when the target is KAKTUS.

\section{Method}

Participants. Twenty-four participants drawn from the same pool as described for Experiment 1 took part in Experiment 5.

Procedure. The procedure was the same as in Experiment 1, except that the prime stimuli were followed by percent signs instead of hash marks.

Materials. There were 72 target words (see Appendix D). All target words were bisyllabic
Dutch verbs, either in their infinitive form or in their past tense form. The infinitive form is homonymous to the first and third person plural form in the present tense. Target words were grouped into pairs such that they overlapped in their first four segments. The infinitive form targets had a CV syllable as their first syllable (e.g., hui.len), while past tense targets began with a CVC syllable (e.g., huil.de). All target words consisted of six segments. The mean frequency of occurrence per one million word forms was 592.6 for CVC targets and 313.3 for the CV targets as determined by CELEX.

There were five types of related primes. C, $\mathrm{CV}$, and CVC primes were identical for both members of a pair (e.g., h\%\%\%\%\%, hui\%\%\%, and huil $\% \%$ for HUILEN and HUILDE). The remaining two related primes were different for the two members of a pair (e.g., huile\% and huilen for HUILEN, and huild\% and huilde for HUILDE). Because all targets had a diphthong in their first syllable, there was no difference in phonological vowel length between the different related primes. Neutral primes were identical for all targets, i.e., $\% \& \$ \% \% \%$.

Design. Experiment 5 had a within-participants design. Participants received each target six times, once in each priming condition. The 432 prime-target pairs were grouped into six different blocks such that each target word appeared only once within a block. The priming conditions were equally distributed across blocks. Each participant received all blocks, but the order of blocks was counterbalanced across participants. Items were randomized individually for each participant within blocks with the constraint that the Prime and the Target structure of trials immediately following one another were never the same.

\section{Results}

Naming latencies shorter than $300 \mathrm{~ms}$ and longer than $1000 \mathrm{~ms}$ were counted as errors (less than $1 \%$ of the data). The mean naming latencies and error rates are summarized in Table 7. Analyses of variance were run with Target Structure (CV or CVC), Prime Structure (C, $\mathrm{CV}, \mathrm{CVC}, \mathrm{CVCV} / \mathrm{CVCC}, \mathrm{CVCVC} / \mathrm{CVCCV}$, or 
TABLE 7

Mean Naming Latencies (in ms) and Percentage of Errors (in Parentheses) in Experiment 5

\begin{tabular}{|c|c|c|c|}
\hline \multirow[b]{2}{*}{ Prime structure } & \multicolumn{2}{|c|}{ Target structure } & \multirow[b]{2}{*}{ Mean } \\
\hline & $\begin{array}{c}\text { CV words } \\
\text { (e.g., HUILEN) }\end{array}$ & $\begin{array}{c}\text { CVC words } \\
\text { (e.g., HUILDE) }\end{array}$ & \\
\hline $\mathrm{C}$ (e.g., h\%\%\%\%\%\%) & $469(2.3)$ & $472(2.8)$ & 470 \\
\hline CV (e.g., hui\%\%\%) & $455(2.4)$ & $457(3.4)$ & 456 \\
\hline CVC (e.g., huil\%\%) & $449(1.6)$ & $447(3.1)$ & 448 \\
\hline CVCV/CVCC (e.g., huile\%/huild\%) & $446(2.1)$ & $445(2.3)$ & 445 \\
\hline CVCVC/CVCCV (e.g., huilen/huilde) & $443(2.3)$ & $441(2.7)$ & 442 \\
\hline Neutral (e.g., \%\&\$\%\%\%) & $483(3.6)$ & $483(3.6)$ & 483 \\
\hline
\end{tabular}

neutral), and Block $(1,2,3,4,5$, or 6$)$ as independent variables.

Error rates. There were $2.68 \%$ errors altogether. None of the main effects or interactions were significant.

Reaction times. The main effect of Block was significant $\left(F_{1}(5,115)=7.28, M S_{\mathrm{e}}=3211.15\right.$, $p<.001 ; F_{2}(5,350)=58.93, M S_{\mathrm{e}}=607.54$, $p<.001)$, reflecting the fact that naming latencies decreased with repetition. Target words were named slowest in the first block (476 ms), but there was little difference in naming latency for the following blocks (means for blocks 2 through 6: $455 \mathrm{~ms}, 451 \mathrm{~ms}, 456 \mathrm{~ms}, 455 \mathrm{~ms}$, and $453 \mathrm{~ms})$. Because Block did not interact with any other variable, the data were collapsed across blocks.

The main effect of Target Structure was not significant $\left(F_{1}(1,23)<1 ; F_{2}(1,70)<1\right)$ and did not interact with Prime Structure $\left(F_{1}(5,115)<\right.$ $\left.1 ; F_{2}(5,350)<1\right)$. Because there were no differences between the two target word categories, the data were collapsed across Target Structures in the subsequent analyses.

Most importantly, the main effect of Prime Structure was highly significant $\left(F_{1}(5,115)=\right.$ $182.98, M S_{\mathrm{e}}=33.77, p<.001 ; F_{2}(5,355)=$ 117.19, $\left.M S_{\mathrm{e}}=158.24, p<.001\right)$. Naming latencies were longest in the neutral priming condition and decreased when the segmental overlap between prime and target was increased. Except for the $3 \mathrm{~ms}$ differences between the CVC and the CVCV/CVCC and between the CVCV/CVCC and the identity priming condition, all differences between the priming conditions were significant by participants and items $(p<.05)$ as revealed by Newman-Keuls post hoc comparisons.

\section{Discussion}

The results did not reveal a syllable priming effect as indicated by the lack of an interaction between Prime Type and Target Type. Instead, strong facilitation effects were obtained for all related primes when compared to a neutral control condition. As predicted by the segmental overlap hypothesis, the priming effects increased with increased segmental overlap between primes and targets. These results are in line with the results obtained in the previous four experiments, indicating that the segmental overlap effect is not artifactual. Thus, even when the methodology was almost identical to that used by Ferrand et al. (1996, 1997), no syllable priming effect was obtained in Dutch. Furthermore, the results of Experiment 5 are important because they show that the results of the previous experiments can be generalized to verbs as well as nouns.

\section{GENERAL DISCUSSION}

The results of the present experiments showed no sign of a syllable priming effect in Dutch. Visually masked primes that corresponded to the first syllable of a target did not yield larger facilitation effects than primes that were shorter or longer than the target's first syllable. In all five naming experiments, orthographically related primes that corresponded to the initial segments of the target yielded signif- 
icant facilitation effects when compared with neutral control primes.

The fact that the magnitude of the facilitation effects obtained in all five experiments increased when the segmental overlap between prime and target was increased agrees with Baumann's (1995) results. She had participants produce encliticized verb forms upon the presentation of a visual prompt while interfering stimuli were presented auditorily. The target utterances were bisyllabic and began either with a $\mathrm{CV}$ or with a CVC syllable, while the interfering stimuli were monosyllabic and either matched the targets' first syllable or not. Baumann did not find a syllable match effect. Instead, she consistently obtained facilitation with both $\mathrm{CV}$ and CVC phonologically related interfering stimuli when compared to a pink, noise ${ }^{3}$ control condition. In general, interfering stimuli yielded larger facilitation when they had CVC structure than when they had CV structure. The same results was found in the present study with different materials and a different experimental paradigm that had the advantage of minimizing strategic effects.

Interestingly, Boelhouwer (1998) also failed to find a syllable priming effect in Dutch word naming using the masked priming paradigm, although he used exactly the same method as described in Ferrand et al. (1996). Using a prime exposure duration of $28 \mathrm{~ms}$, he found a slight but non-significant advantage for CVC over CV primes. This effect increased when the prime exposure duration was extended to $70 \mathrm{~ms}$. Thus, his data are in line with the segmental overlap hypothesis and contradict the syllable priming hypothesis.

Although the results obtained in this study are in line with other data found with Dutch (Baumann, 1995; Boelhouwer, 1998), they are at variance with the results from a recent study by Ferrand et al. (1996) reporting a syllable priming effect in French. Possibly this has to do with the fact that French and Dutch differ in phono-

\footnotetext{
${ }^{3}$ As opposed to white noise, which has a uniform distribution of energy over the whole spectrum (20-20.000 Hz), pink noise has less energy in the higher frequency part of the spectrum and is therefore closer to the speech signal than white noise.
}

logical structure. French is traditionally considered to be a syllable-timed language, whereas Dutch is stress-timed. With French, clear syllabic effects have been obtained in perception (Mehler et al., 1981; Pallier et al., 1993), whereas in Dutch the syllable is not used as a functional unit in speech perception (Cutler, 1997; Vroomen \& de Gelder, 1994; but see also Zwitserlood et al., 1993). However, Evinck (1997) failed to find a syllable priming effect in French, even though she used the same materials and almost the same method as in the Ferrand et al. (1996) study. Thus, the syllable priming effect in French does not seem to be very stable.

The WEAVER model of speech production provides an account for the segmental overlap effect found in Dutch. WEAVER (Word-form Encoding by Activation and VERification) is a spreading-activation based computer network model developed by Roelofs (1996, 1997a, 1997b). It adopts Dell's (1986) assumption of word form retrieval by the spread of activation and Levelt's (1992) assumption of on-line syllabification and access to a syllabary (Levelt \& Wheeldon, 1994). The model has several strata, each of which consists of nodes and links. The word-form stratum, for example, includes metrical structure, morpheme, segment, and syllable program nodes, and links between them (Roelofs, 1997a). A key feature of the WEAVER model is the assumption of on-line syllabification. This distinguishes it from classical models of speech production (e.g., Dell, 1986, 1988; Shattuck-Hufnagel, 1979) which assume that the syllables of a word are stored in the mental lexicon.

Storing words as sequences of syllables poses serious problems when the syllable affiliation of a segment changes due to morpho-phonological processes such as affixation or cliticization (for examples, see Roelofs, 1997a). WEAVER deals with the flexibility of syllable affiliation by computing instead of storing syllabifications. During phonological encoding, the segments and the metrical structure of a morpheme are selected. The metrical structure includes information about the number of syllables and the 
location of lexical stress but not the CV structure (Roelofs \& Meyer, 1998). Links between morpheme and segment nodes specify the serial position of the segments within the morpheme. Furthermore, the links between segments and syllable programs are marked for possible syllable positions (onset, nucleus, coda). For example, an $/ \mathrm{n} /$ may occur in the coda of a preceding syllable or in the onset of a following syllable. A prosodification process associates the selected segments to a syllable node within the metrical structure. The assignment of actual syllable positions is done on-line from left to right following universal and language-specific syllabification rules. Phonological rather than lexical words form the domain of syllabification (Booij, 1995). Because adjacent morphemes or words may be prosodified together, thereby forming new phonological words, the prosodification process in WEAVER can account for cross-morpheme and cross-word syllabification. A review of empirical support for the on-line syllabification adopted in WEAVER can be found in Roelofs (1997a).

During phonetic encoding a syllable program node is selected that matches the syllable positions which were assigned on-line to the segments. This process may include the access to a mental syllabary. If no syllable program node matches the syllabified sequence of segments, a motor program for the syllable has to be generated "from scratch." Finally, the parameters for pitch, loudness, and duration are set, and the motor programs are made available to the articulators which produce overt speech.

It is important to note that in WEAVER, segments are not specified for syllable positions but only for their serial position within a word. In particular, a $\mathrm{C}_{1} \mathrm{VC}_{2}$ prime activates all syllables in the mental syllabary containing any of the elements $\mathrm{C}_{1}, \mathrm{C}_{2}$, and $\mathrm{V}$; this includes both the syllable $\mathrm{C}_{1} \mathrm{~V}$ and the syllable $\mathrm{C}_{1} \mathrm{VC}_{2}$. Therefore, the model does not predict a syllable match effect in speech production. In contrast, WEAVER predicts a segmental overlap effect because the masked syllable primes preactivate segments that are not specified for syllable position.

In computer simulations with $\mathrm{CV}$ and $\mathrm{CVC}$ target words and monosyllabic CV and CVC spoken primes that were phonologically related or unrelated to the beginning of the targets, Roelofs (personal communication) obtained facilitation effects for the related as compared to the unrelated primes. However, CVC primes yielded more facilitation than $\mathrm{CV}$ primes for both $\mathrm{CV}$ and CVC targets. For example, priming a CV target with a CV prime yielded $55 \mathrm{~ms}$ facilitation, while priming the same target with a CVC prime yielded $81 \mathrm{~ms}$ facilitation. Similarly, for CVC targets a facilitation effect of 30 ms was achieved with $\mathrm{CV}$ primes, whereas CVC primes yielded $40 \mathrm{~ms}$ facilitation. Thus, the results of the computer simulations agree with the pattern of data obtained in the present experiments.

As opposed to Dutch, French has a simpler syllable structure with relatively clear boundaries between the syllables of a word. If it is assumed that French segments are marked for syllable position in the input lexicon, as suggested by the perception studies in French, the syllable match effect in French can be accounted for the WEAVER without changing the assumptions about speech production in the model. One of the basic assumptions of the model is that active phonological segments in the perceptual network can directly affect the corresponding segment nodes in the production lexicon (Levelt et al. in press). The segments occurring in the French visually masked primes already contain information about their syllable positions. Consider, for example, the prime pal and the target pal.mier. The prime preactivates segments specified for syllable position in the perceptual network, e.g., $p_{\text {onset }}, a_{\text {nucleus, }}$ and $l_{\text {coda }}$. This perception information agrees with the syllable positions that are computed on-line for the segments of the first syllable of pal.mier in production and results in a syllable match effect. From this account it also becomes clear that the syllable match effect in French does not interact with a segmental overlap effect; pal does not prime pa.lace because the /1/ in pal is specified for the coda position, whereas the $/ 1 /$ in pa.lace occurs in onset position. That is, there is a positional mismatch which results in the failure of CVC primes to yield a priming effect for 
CV targets in French. Similarly, the failure to obtain a syllable priming effect in Dutch speech production can then be interpreted as a consequence of the absence of syllable position information by perception.

Contrary to the results found with Dutch materials, Ferrand et al. (1997) reported a syllable priming effect for English speech production. Dutch is similar to English with respect to syllable structure. On theoretical grounds, English and Dutch may have been expected to behave similarly in syllable priming experiments. However, in the present study we did not find a syllable priming effect for Dutch speech production. In the following we discuss several potential resolutions for this discrepancy.

One possible explanation may lie in the different prime exposure durations used in this study (50 ms) and in the Ferrand et al. (1997) study $(29 \mathrm{~ms})$ and the correlated differences in prime processing. In spite of the fact that Ferrand et al. $(1996,1997)$ obtained relatively large facilitation effects with extremely short prime exposure durations ( $29 \mathrm{~ms}$ ), in our labratory we did not obtain the same size of effects in pilot experiments wit a comparable prime exposure duration $(33 \mathrm{~ms})$. Therefore, a prime exposure duration of $50 \mathrm{~ms}$ was chosen for the five experiments reported in the present study. Ferrand et al. (1996, 1997) argued that the syllable prime activated sublexical orthographic units that subsequently sent their activation to syllabic output units. That is, the syllable priming interpretation strongly depends on the assumption of a direct connection between orthographic input units and articulatory output units that are syllabically structured. Thus, within Ferrand et al.'s (1996, 1997) framework one may argue that the difference in results was due to the difference in prime exposure duration: With an exposure duration of only $29 \mathrm{~ms}$, only early activation of motor programs by orthographic information was tested. By contrast, when primes were presented for $50 \mathrm{~ms}$, additional phonological processes were tapped, and this may explain the difference between the English and the Dutch results. However, it is known that phonological effects emerge automatically at very early stages in the processing of printed stimuli (Ferrand \& Grainger, 1992, 1993, 1994; van Orden, 1987; Perfetti, Bell, \& Delaney, 1988; Perfetti \& Bell, 1991; Rayner et al., 1995; see Berent \& Perfetti, 1995 for a recent review). Since orthographic and phonological relatedness between primes and targets was confounded in the Ferrand et al. (1996, 1997) studies as well as in this study, no clear statement can be made about the nature of the priming effect.

A problem that arises when the syllable priming effect is interpreted as an orthographic priming effect has to do with the direct mapping of activation from sublexical orthographic units to syllabic output units, at least with respect to the English data reported in Ferrand et al. (1997). English is known to have a relatively "deep" orthography (Perfetti \& Bell, 1991); i.e., the mapping of graphemic information onto phonological information is less direct than in Dutch, which has a relatively "shallow" orthography. The pronunciation of syllables in English often depends on the context in which they occur; i.e., many syllables have inconsistent pronunciations. The syllable $d e$, for instance, is pronounced as [de] in debit, as [di] in decent, and as [dei] in debut. Jared and Seidenberg (1990) showed that inconsistent spelling-sound correspondences affect the naming of polysyllabic (low-frequency) words. The inspection of the experimental materials used in the Ferrand et al. (1997) study shows that many of their syllable primes have inconsistent pronunciations. To give an example, the syllable $\mathrm{bal}$, which was a $\mathrm{CVC}$ prime in their first experiment both for the target balcony /bæl.kəni/ and for the target balance /bæ[1]əns/, can be pronounced as /bæl/ (e.g., in the two target words), but also as /bol/ (e.g., in balding /bol.dIn/), /beIl/ (e.g., in baleful /beIl.ful/), /bəl/ (e.g., in balloon /bə.lun.), /ba/ (e.g., in balmy /ba.mi/), or /bpl/ (e.g., in balsa /bpl.sə/). But how does the speech production system know that the activation from $\langle\mathrm{b}\rangle$, $<\mathrm{a}>,<\mathrm{l}>$ has to be mapped onto/bæl/ and not onto any of the other possible pronunciations for bal? Ferrand et al. (1997) do not discuss this issue, and it is not clear how their network model could account for this point.

Another, possibly more serious problem is 
that participants may have applied a strategy in the crucial experiment of the Ferrand et al. (1997) study. In their fifth experiment, they exclusively used CV target words. Ferrand et al. (1997) observed a syllable match effect in this experiment which might have been due to the fact that participants noticed that all items began with a CV syllable and thus used this information strategically to trigger their articulatory responses. Primes that were compatible with this structure, i.e., CV primes, facilitated naming, whereas primes that were incompatible did not. That is, participants might have been able to strategically modify the type of information they used to trigger their response as a function of the type of materials in the experiment (for a related proposal see Lupker, Brown, \& Colombo, 1997).

To summarize, there are arguments that make the interpretation of the syllable priming effect as an orthographic effect in English given by Ferrand et al. (1997) appear doubtful. We suggest here that the priming effect in the Ferrand et al. $(1996,1997)$ studies and in the present study are not only orthographic but also phonological in nature. The visually masked primes first activate orthographic units, but these do not send activation directly to articulatory output units. Instead, they activate sublexical phonological units which correspond to segments. In the case of French, these segments are specified for syllable position during perception, and the production system can make use of this addi- tional information, which results in a syllable match effect. In the case of Dutch, however, only the phonological segments, but not their syllable position, become preactivated when the prime is being processed. Hence, there is no syllable priming but a segmental overlap effect in Dutch. The question "why did Ferrand et al. (1997) report a syllable priming effect for English?' remains unanswered. On theoretical grounds, Dutch and English should behave similarly. However, so far a picture naming experiment has not yet been carried out with English materials. Since English has a relatively "deep" orthography, this may be the crucial experiment to solve the controversy.

\section{CONCLUSION}

The results of the masked priming experiments reported in this study showed that there is no syllable priming effect in Dutch speech production. However, orthographically and phonologically related primes facilitated the naming of word and picture targets significantly. The fact that the priming effect increase with an increase in segmental overlap between prime and target and was independent of the syllabic structure of the target word is accounted for by a segmental overlap effect. We suggested that the effect is due to the preactivation of sublexical phonological units. The WEAVER model of speech production (Roelofs, 1996, 1997a, 1997b) predicts such a segmental overlap effect.

\section{APPENDIX A}

Stimulus Materials in Experiments 1 and 2

\begin{tabular}{lll}
\hline & \multicolumn{1}{c}{ Target structure } & \\
\hline \multicolumn{1}{c}{ CV targets } & \multicolumn{1}{c}{ CVC targets } & CV[C]targets \\
\hline ketel ('kettle') & borstel ('brush') & visser ('fisherman') \\
degen ('sword') & wortel ('carrot') & ridder ('knight') \\
lama ('llama') & hamster ('hamster') & passer ('compass') \\
jager ('hunter') & lifter ('hitchhiker') & mossel ('mussel') \\
motor ('motorbike') & cirkel ('circle') & lasso ('lasso') \\
roker ('smoker') & pinda ('peanut') & kussen ('pillow') \\
toren ('tower') & kaktus ('cactus') & ketting ('chain') \\
vogel ('bird') & masker ('mask') & kapper ('hairdresser') \\
foto ('photograph') & filter ('filter') & wekker ('alarm clock') \\
\hline
\end{tabular}


Target structure

CV targets

CVC targets

CV[C]targets

beker ('mup')

kegel ('cone')

zuster ('sister')

tunnel ('tunnel')

sofa ('sofa')

koning ('king')

dokter ('docter')

herder ('shepherd')

tekkel ('dachshund')

kano ('canoe')

halter ('dumb-bell')

varken ('pig')

bunker ('bunker')

robot ('robot')

panty ('tights')

bezem ('broom')

tempel ('temple')

tuba ('tuba')

bumper ('bumper')

sikkel ('sickle')

puzzel ('puzzle')

monnik ('monk')

mammoet ('mammoth')

ladder ('ladder')

kassa ('cash register')

fakkel ('torch')

\section{APPENDIX B}

\section{Stimulus Materials in Experiment 3 (Set A)}

Target structure

\begin{tabular}{ll}
\hline \multicolumn{1}{c}{ CV[C]wprds } & \multicolumn{1}{c}{ CVC words } \\
\hline ballast ('ballast') & balsem ('balsam') \\
borrel ('drink') & borstel ('brush') \\
fakkel ('torch') & faktor ('factor') \\
hennep ('hemp') & hendel ('trade') \\
herrie ('noise') & herder ('shepherd') \\
Holland ('Holland') & holster ('holster') \\
horror ('horror') & horzel ('hornet') \\
kaffer ('boor') & kaftan ('caftan') \\
kerrie ('curry') & kermis ('fairground') \\
ketting ('chain') & ketjap ('soya sauce') \\
kikker ('frog') & kikvors ('frog') \\
korrel ('grain') & korpus ('corpus') \\
lasso ('lasso') & laster ('slander') \\
lekkers ('sweet') & lekto ('lecturer') \\
linnen ('linen') & linde ('lime tree') \\
manna ('manna') & mantel ('coat') \\
monnik ('monk') & monster ('monster') \\
pellen ('peel') & pelgrim ('pilgrim') \\
penning ('penny') & pendel ('hanging lamp') \\
pollen ('pollen') & polka ('polka') \\
tennis ('tennis') & tensie ('pressure') \\
\hline
\end{tabular}

Stimulus Materials in Experiment 3 (Set B)

\begin{tabular}{|c|c|}
\hline \multicolumn{2}{|c|}{ Target structure } \\
\hline $\mathrm{CV}[\mathrm{C}]$ words & CVC words \\
\hline bakker ('baker') & banjo ('banjo') \\
\hline bobbel ('bubble') & binder ('binder') \\
\hline buffel ('buffalo') & filter ('filter') \\
\hline hobby ('hobby') & herberg ('inn') \\
\hline hommel ('drone') & hertog ('duke') \\
\hline kapper ('hairdresser') & kaktus ('cactus') \\
\hline
\end{tabular}

kassa ('cash register')

kennel ('kennel')

koffie ('coffee')

koppel ('couple')

letter ('letter')

lotto ('lottery')

makker ('pal')

mokka ('mocha')

peddel ('paddle')

rabbi ('rabbi')

rommel ('lumber')

teller ('counter')

toffee ('toffee')

tunnel ('tunnel')

wekker ('alarm clock')
Target structure

CVC words

kelder ('cellar')

kapsel ('hair-style')

kaste ('caste')

kolder ('nonsense')

letsel ('injury')

wimpel ('pennant')

marmer ('marble')

mentor ('tutor')

polder ('polder')

porto ('postage')

pinda ('peanut')

handel ('trade')

tempel ('temple')

kansel ('pulpit')

wortel ('carrot')

\section{APPENDIX C}

\section{Stimulus Materials in Experiment 4 (Set A)}

Target structure

\begin{tabular}{ll}
\hline \multicolumn{1}{c}{ CV words } & \multicolumn{1}{c}{ CVC words } \\
\hline balie ('counter') & balsem ('balsam') \\
bonus ('bonus') & bonsai ('bonsai') \\
deken ('blanket') & deksel ('lid') \\
deler ('divisor') & delta ('delta') \\
donor ('donor') & donder ('thunder') \\
fakir ('fakir') & faktor ('factor') \\
hamer ('hammer') & hamster ('hamster') \\
harem ('harem') & harnas ('armour') \\
heler ('receiver') & helper ('helper') \\
honing ('honey') & honderd ('hundred') \\
\hline
\end{tabular}


Target structure

CV words

CVC words

kano ('canoe')

kaper ('hijacker')

kerel ('fellow')

ketel ('kettle')

kilo ('kilo')

kola ('kola')

koren ('corn')

lening ('loan')

maning ('dun')

merel ('blackbird')

polo ('polo')

kansel ('pulpit')

lente ('spring')

mantel ('coat')

mergel ('marl')

polder ('polder') kapsel ('hair-style')

kermis ('fairground')

ketjap ('soja sauce')

kilte ('chilliness')

kolder ('nonsense')

korpus ('corpus')

\section{Stimulus Materials in Experiment 4 (Set B)}

Target structure

\begin{tabular}{ll}
\hline $\mathrm{CV}$ words & CVC words \\
\hline
\end{tabular}

forum ('forum')

foto ('photograph')

kader ('framework')

motor ('motorbike')

visie ('vision')

basis ('basis')

tepel ('nipple')

dosis ('dose')

ruzie ('row')

bodem ('bottom')

poker ('poker')

boter ('butter')

fabel ('fable')

lepel ('spoon')

liter ('litre')

tafel ('desk')

sofa ('sofa')

bezem ('broom')

divan ('divan')

beker ('mug')

laken ('sheet')

\author{
filter ('filter') \\ firma ('firm') \\ kelder ('cellar') \\ mensa ('refectory') \\ wodka ('vodka') \\ marmer ('marble') \\ tosti ('toasted sandwich') \\ kaktus ('cactus') \\ rosbief ('roast beef') \\ moslim ('Muslim') \\ panter ('panther') \\ kosmos ('cosmos') \\ wortel ('carrot') \\ mentor ('tutor') \\ pinda ('peanut') \\ tempo ('tempo') \\ zombie ('zombie') \\ binder ('binder') \\ handel ('trade')
}

tempel ('temple')

lakmoes ('litmus')
Target structure

\begin{tabular}{|c|c|}
\hline $\mathrm{CV}$ words & CVC words \\
\hline dienen ('to serve') & diende ('served') \\
\hline doelen ('to aim') & doelde ('aimed') \\
\hline $\begin{array}{l}\text { duimen ('to keep ones' } \\
\text { fingers crossed') }\end{array}$ & $\begin{array}{l}\text { duimde ('kept one's fingers } \\
\text { crossed') }\end{array}$ \\
\hline geuren ('to smell') & geurde ('smelt') \\
\hline gieren ('to screech') & gierde ('screeched') \\
\hline hijgen ('to pant') & hijgde ('panted') \\
\hline huilen ('to cry') & huilde ('cried') \\
\hline jeuken ('to itch') & jeukte ('itched') \\
\hline keuren ('to examine') & keurde ('examined') \\
\hline $\begin{array}{l}\text { kiemen ('to } \\
\text { germinate') }\end{array}$ & kiemde ('germinated') \\
\hline koelen ('to cool') & koelde ('cooled') \\
\hline leunen ('to lean') & leunde ('leant') \\
\hline lijmen ('to glue') & lijmde ('glued') \\
\hline loeren ('to lurk') & loerde ('lurked') \\
\hline noemen ('to call') & noemde ('called') \\
\hline peilen ('to plot') & peilde ('plotted') \\
\hline piepen ('to squeak') & piepte ('squeaked') \\
\hline rijmen ('to rhyme') & rijmde ('rhymed') \\
\hline rijpen ('to ripen') & rijpte ('ripened') \\
\hline roeren ('to stir') & roerde ('stirred') \\
\hline ruilen ('to change') & ruilde ('changed') \\
\hline ruisen ('to roar') & ruiste ('roared') \\
\hline seinen ('to signal') & seinde ('signaled') \\
\hline sieren ('to adorn') & sierde ('adorned') \\
\hline $\begin{array}{l}\text { toeren ('to go on a } \\
\text { trip') }\end{array}$ & toerde ('went on a trip') \\
\hline vieren ('to celebrate') & vierde ('celebrated') \\
\hline voegen ('to place') & voegde ('placed') \\
\hline voelen ('to feel') & voelde ('felt') \\
\hline voeren ('to feed') & voerde ('fed') \\
\hline woelen ('to dig') & woelde ('dug') \\
\hline zeilen ('to sail') & zeilde ('sailed') \\
\hline zeuren ('to grumble') & zeurde ('grumbled') \\
\hline zoemen ('to hum') & zoemde ('hummed') \\
\hline zoenen ('to kiss') & zoende ('kissed') \\
\hline
\end{tabular}

\section{REFERENCES}

Baayen, R. H., Piepenbrock, R., \& Gulikers, L. (1995). The CELEX lexical database (CD-ROM). Philadelphia: Linguistic Data Consortium, University of Pennsylvania.

Bagemihl, B. (1995). Language games and related areas. In J. A. Goldsmith (Ed.), The handbook of phonological theory (pp. 697-712).. Cambridge, Oxford: Blackwell.

Bajo, M.-T. (1988). Semantic facilitation with pictures and words. Journal of Experimental Psychology: Learning, Memory, and Cognition, 14, 579-589.

Baumann, M. (1995). The production of syllables in connected speech. Ph.D. dissertation, Nijmegen University. boende ('polished')

deugde ('was suitable for') for') 
Berg, T. (1988). Die Abbildung des Sprachproduktionsprozesses in einem Aktivationsflußmodell: Untersuchungen an deutschen und englischen Versprechern [The representation of the speech production process in a spreading activation model: Studies of German and English speech errors]. Tubingen: Niemeyer.

Berent, I., \& Perfetti, C. A. (1995). A rose is a REEZ: The two-cycles model of phonology assembly in reading English. Psychological Review, 102, 146-184.

Boelhouwer, B. (1998). From letter strings to phonemes: The role of orthographic context in phonological recording. Ph.D. dissertation, Nijmegen University.

Booij, G. (1995). The phonology of Dutch. Oxford: Clarendon Press.

Brown, A. S. (1991). A review of the tip-of-the-tongue experience. Psychological Bulletin, 109, 204-223.

Brown, C. M., \& Hagoort, P. (1993). The processing nature of the N400: Evidence from masked priming. Journal of Cognitive Neuroscience, 5, 34-44.

Burke, D., MacKay, D. G., Worthley, J. S., \& Wade, E. (1991). On the tip of the tongue: What causes word finding failures in young and older adults? Journal of Memory and Language, 30, 237-246.

Burnage, G. (1990). CELEX. A guide for users. Nijmegen: Centre for Lexical Information.

Bruck, M., Treiman, R., \& Caravolas, M. (1995). Role of the syllable in the processing of spoken English: Evidence from a nonword comparison task. Journal of Experimental Psychology: Human Perception and Performance, 21, 469-479.

Caramazza, A., \& Miozzo, M. (1997). The relation between syntactic and phonological knowledge in lexical access: Evidence from the 'tip-of-the-tongue' phenomenon. Cognition, 64, 309-343.

Cowan, N., Leavitt, L. A., Massaro, D. W., \& Kent, R. D. (1982). A fluent backward talker. Journal of Speech and Hearing Research, 25, 48-53.

Cowan, N., Braine, M. D. S., \& Leavitt, L. A. (1985). The phonological and metaphonological representation of speech: Evidence from fluent backward talkers. Journal of Memory and Language, 24, 679-698.

Crompton, A. (1981). Syllables and segments in speech production. Linguistics, 19, 663-716.

Cutler, A. (1997). The syllable's role in the segmentation of stress languages. Language and Cognitive Processes, 12, 839-845.

Davis, C., \& Forster, K. I. (1994). Masked orthographic priming: The effect of prime-target legibility. The Quarterly Journal of Experimental Psychology, 47A, 673-697.

Dell, G. S. (1986). A spreading-activation theory of retrieval in sentence production. Psychological Review, 93, 283-321.

Dell, G. S. (1988). The retrieval of phonological forms in production: Tests of predictions from a connectionist model. Journal of Memory and Language, 27, 124142 .

Dupoux, E. (1993). The time course of prelexical process- ing: The syllabic hypothesis revisited. In G. T. M. Altmann \& R. Shillcock (Eds.), Cognitive models of speech processing: The second Sperlonga meeting (pp. 81-114). Hillsdale, NJ: Erlbaum.

Evinck, S. (1997). Production de la parole en français: Investigation des unités impliquées dans l'encodage phonologique des mots [Speech production in French: Investigation of the units implied during the phonological encoding of words]. Ph.D. dissertation, Bruxelles University.

Fallows, D. (1981). Experimental evidence for English syllabification and syllable structure. Journal of Linguistics, 17, 309-317.

Ferrand, L., \& Grainger, J. (1992). Phonology and orthography in visual word recognition: Evidence from masked nonword priming. Quarterly Journal of Experimental Psychology, 45A, 353-372.

Ferrand, L., \& Grainger, J. (1993). The time course of orthographic and phonological code activation in the early phases of visual word recognition. Bulletin of the Psychonomic Society, 31, 119-122.

Ferrand, L., \& Grainger, J. (1994). Effects of orthography are independent of phonology in masked form priming. The Quarterly Journal of Experimental Psychology, 47A, 365-382.

Ferrand, L., Grainger, J., \& Segui, J. (1994). A study of masked form priming in picture and word naming. Memory \& Cognition, 22, 431-441.

Ferrand, L., Segui, J., \& Grainger, J. (1996). Masked priming of word and picture naming: The role of syllabic units. Journal of Memory and Language, 35, 708-723.

Ferrand, L., Segui, J., \& Humphreys, G. W. (1997). The syllable's role in word naming. Memory \& Cognition, 35, $458-470$.

Forster, K. I. (1987). Form-priming with masked primes: The best match hypothesis. In M. Coltheart (Ed.), Attention and Performance XII. The psychology of reading (pp. 127-146). Hillsdale, NJ: Erlbaum.

Forster, K. I. (1993). Form-priming and temporal integration in word recognition. In G. T. M. Altmann \& R. Shillcock (Eds.), Cognitive models of speech processing: The second Sperlonga meeting (pp. 467-495). Hillsdale, NJ: Erlbaum.

Forster, K. I., \& Chambers, S. (1973). Lexical access and naming time. Journal of Verbal Learning and Verbal Behavior, 12, 627-635.

Forster, K. I., and Davis, C. (1984). Repetition priming and frequency attenuation in lexical access. Journal of Experimental Psychology: Learning, Memory, and Cognition, 10, 680-698.

Forster, K. I., \& Davis, C. (1991). The density constraint on form-priming in the naming task: Interference effects from a masked prime. Journal of Memory and Language, 30, 1-25.

Forster, K. I., Davis, C., Schoknecht, C., \& Carter, R. (1987). Masked priming with graphemically related forms: Repetition or partial activation? The Quarterly Journal of Experimental Psychology, 39A, 211-251. 
Fowler, C. A., Treiman, R., \& Gross, J. (1993). The structure of English syllables and polysyllables. Journal of Memory and Language, 32, 115-140.

Frederiksen, J. R., \& Kroll, J. F. (1976). Spelling and sound: Approaches to the internal lexicon. Journal of Experimental Psychology: Human Perception and Performance, 2, 361-379.

Gillis, S., \& de Schutter, G. (1996). Intuitive syllabification: Universals and language specific constraints. Journal of Child Language, 23, 487-514.

Glaser, W. R. (1992). Picture naming. Cognition, 42, 61105.

Grainger, J., \& Ferrand, L. (1996). Masked orthographic and phonological priming in visual word recognition and naming: Cross-task comparisons. Journal of Memory and Language, 35, 623-647.

Hombert, J.-M. (1986). Word games: Some implications for analysis of tone and other phonological constructs. In J. J. Ohala \& J. J. Jaeger (Eds.), Experimental phonology (pp. 175-186). Orlando: Academic Press.

Humphreys, G. W., Evett, L. J., Quinlan, P. T., \& Besner, D. (1987). Orthographic priming: Qualitative differences between priming from identified and unidentified primes. In M. Coltheart (Ed.), Attention and Performance XII. The psychology of reading (pp. 105-125). Hillsdale, NJ: Erlbaum.

Huttenlocher, J., \& Kubicek, L. F. (1983). The source of relatedness effects on naming latency. Journal of Experimental Psychology: Learning, Memory, and Cognition, 9, 486-496.

Jared, D., \& Seidenberg, M. S. (1990). Naming multisyllabic words. Journal of Experimental Psychology: Human Perception and Performance, 16, 92-105.

Klapp, S. T. (1974). Syllable-dependent pronunciation latencies in number naming: A replication. Journal of Experimental Psychology, 102, 1138-1140.

Klapp, S. T., Anderson, W. G., \& Berrian, R. W. (1973). Implicit speech in reading reconsidered. Journal of Experimental Psychology, 100, 368-374.

Klapp, S. T., \& Erwin, C. I. (1976). Relation between programming time and duration of the response being programmed. Journal of Experimental Psychology: Human Perception and Performance, 2, 591-598.

Lefkowitz, N. (1991). Talking backwards, looking forwards. The French language game Verlan. Tübingen: Narr.

Levelt, W. J. M. (1989). Speaking. From intention to articulation. Cambridge, MA: MIT Press.

Levelt, W. J. M. (1992). Accessing words in speech production: Stages, processes and representations. Cognition, 42, 1-22.

Levelt, W. J. M. (1993). Timing in speech production with special reference to word from encoding. Annals of the New York Academy of Sciences, 682, 283-295.

Levelt, W. J. M., Roelofs, A., \& Meyer, A. S. (in press). A theory of lexical access in speech production. Behavioral and Brain Sciences.

Levelt, W. J. M., \& Schiller, N. O. (in press). Is the syllable frame stored? (Commentary on the BBS target article "The frame" content theory of evolution of speech production"' by Peter F. MacNeilage). Behavioral and Brain Sciences.

Levelt, W. J. M., \& Wheeldon, L. (1994). Do speakers have access to a mental syllabary? Cognition, 50, 239-269.

Lovelace, E. (1987). Attributes that come to mind in the TOT state. Bulletin of the Psychonomic Society, 25, 370-372.

Lupker, S. J., Brown, P., \& Colombo, L. (1997). Strategic control in a naming task: Changing routes or changing deadlines? Journal of Experimental Psychology: Learning, Memory, and Cognition, 23, 570-590.

MacKay, D. G. (1970). Spoonerisms: The structure of errors in the serial order of speech. Neuropsychologia, 8, 323-350.

Mehler, J., Dommergues, J. Y., Frauenfelder, U., \& Segui, J. (1981). The syllable's role in speech segmentation. Journal of Verbal Learning and Verbal Behavior, 20, 298-305.

Meijer, P. J. A. (1994). Phonological encoding: The role of suprasegmental structures. Ph.D. dissertation, Nijmegen University.

Meijer, P. J. A. (1996). Suprasegmental structures in phonological encoding: The CV structure. Journal of Memory and Language, 35, 840-853.

Meyer, A. S. (1990). The time course of phonological encoding in language production: The encoding of successive syllables of a word. Journal of Memory and Language, 29, 524-545.

Meyer, A. S. (1991). The time course of phonological encoding in language production: Phonological encoding inside a syllable. Journal of Memory and Language, 30, 69-89.

Meyer, A. S. (1992). Investigation of phonological encoding through speech error analyses: Achievements, limitations, and alternatives. Cognition, 42, 181-211.

Nooteboom, S. (1969). The tongue slips into patterns. In A. G. Sciarone, A. J. von Essen, \& A. A. van Raad (Eds.), Nomen: Leyden studies in linguistics and phonetics (pp. 114-132). The Hague: Mouton.

Nusbaum, H., \& DeGroot, J. (1990). The role of syllables in speech perception. In M. Ziolkowski, M., Noske, \& K. Deaton (Eds.), Papers from the 26th Regional Meeting of the Chicago Linguistic Society. Volume 2: The parasession on the syllable in phonetics \& phonology (pp. 287-317). Chicago: Chicago Linguistic Society.

van Orden, G. C. (1987). A ROWS is a ROSE: Spelling, sound, and reading. Memory \& Cognition, 15, 181198.

Pallier, C., Sebastián-Galles̀, N., Felguera, T., Christophe, A., \& Mehler, J. (1993). Attentional allocation within the syllabic structure of spoken words. Journal of Memory and Language, 32, 373-389.

Perfetti, C. A., Bell, L. C., \& Delaney, S. M. (1988). Automatic (prelexical) phonetic activation in silent word reading: Evidence from backward masking. Journal of Memory and Language, 27, 59-70. 
Perfetti, C. A., \& Bell, L. C. (1991). Phonemic activation during the first $40 \mathrm{~ms}$ of word identification: Evidence from backward masking and priming. Journal of Memory and Language, 30, 473-485.

Rayner, K., Sereno, S. C., Lesch, M. F., \& Pollatsek, A. (1995). Phonological codes are automatically activated during reading: Evidence from an eye movement priming paradigm. Psychological Science, 6, 26-32.

Roelofs, A. (1996). Serial order in planning the production of successive morphemes of a word. Journal of Memory and Language, 35, 854-876.

Roelofs, A. (1997a). Syllabification in speech production: Evaluation of WEAVER. Language and Cognitive Processes, 12, 657-693.

Roelofs, A. (1997b). The WEAVER model of word-form encoding in speech production. Cognition, 64, 249284.

Roelofs, A., \& Meyer, A. S. (1998). Metrical structure in planning the production of spoken words. Journal of Experimental Psychology: Learning, Memory, and Cognition, 24.

Santiago, J., MacKay, D., Palma, A., \& Tudela, P. (1996). Production onset latencies vary with sequential activation processes in hierarchic syllable structures. In J. Hoffman \& A. Sebald (Eds.), Cognitive Psychology in Europe. Proceedings of the 9th Conference of the European Society for Cognitive Psychology (p. 113). Lengerich: Papst.

Schiller, N. O. (1997). The role of the syllable in speech production. Evidence from lexical statistics, metalinguistics, masked priming, and electromagnetic midsagittal articulography. Ph.D. dissertation, Nijmegen University.

Schiller, N. O., Meyer, A. S., Baayen, R. H., \& Levelt, W. J. M. (1996). A comparison of lexeme and speech syllables in Dutch. Journal of Quantitative Linguistics, 3, 8-28.

Schiller, N. O., Meyer, A. S., \& Levelt, W. J. M. (1997). The syllabic structure of spoken words: Evidence from the syllabification of intervocalic consonants. Language and Speech, 40, 103-140.

Segui, J., Dupoux, E., \& Mehler, J. (1990). The role of the syllable in speech segmentation, phoneme identification, and lexical access. In G. Altmann (Ed.), Cognitive models of speech processing. Psycholinguistic and computational perspectives (pp. 263-280). Cambridge, MA: MIT Press.

Sevald, C. A., Dell, G. S., \& Cole, J. S. (1995). Syllable structure in speech production: Are syllables chunks or schemas? Journal of Memory and Language, 34, 807820 .
Shattuck-Hufnagel, S. (1979). Speech errors as evidence for a serial ordering mechanism in sentence production. In W. E. Cooper \& E. C. T. Walker (Eds.), Sentence processing (pp. 295-342). New York: Halsted Press.

Shattuck-Hufnagel, S. (1987). The role of word onset consonants in speech production planning: New evidence from speech error patterns. In E. Keller \& M. Gopnik (Eds.), Motor and sensory processing in language (pp. 17-51). Hillsdale, NJ: Erlbaum.

Shattuck-Hufnagel, S. (1992). The role of word structure in segmental serial ordering. Cognition, 42, 213-259.

Stemberger, J. P. (1982). The nature of segments in the lexicon: Evidence from speech errors. Lingua, 56, 235-259.

Treiman, R. (1983). The structure of spoken syllables: Evidence from novel word games. Cognition, 15, 49-74.

Trieman, R. (1986). The division between onsets and rimes in English syllables. Journal of Memory and Language, 25, 476-491.

Treiman, R., \& Danis, C. (1988). Syllabification of intervocalic consonants. Journal of Memory and Language, 27, 87-104.

Treiman, R., Fowler, C. A., Gross, J., Berch, D., \& Weatherston, S. (1995). Syllable structure or word structure? Evidence for onset and rime units with disyllabic and trisyllabic stimuli. Journal of Memory and Language, 34, 132-155.

Treiman, R., \& Zukowski, A. (1990). Toward an understanding of English syllabification. Journal of Memory and Language, 29, 66-85.

Treiman, R., \& Zukowski, A. (1996). Children's sensitivity to syllables, onsets, rimes, and phonemes. Journal of Experimental Child Psychology, 61, 193-215.

Vroomen, J., \& de Gelder, B. (1994). Speech segmentation in Dutch: No role for the syllable. In Proceedings of the 1994 International Conference on Spoken Language Processing, September 18-22, 1994, Yokohama (pp. 1135-1138).

Wheeldon, L., \& Levelt, W. J. M. (1995). Monitoring the time course of phonological encoding. Journal of Memory and Language, 34, 311-334.

Zwitserlood, P., Schriefers, H., Lahiri, A., \& van Donselaar, W. (1993). The role of syllables in the perception of spoken Dutch. Journal of Experimental Psychology: Learning, Memory, and Cognition, 19, 260-271.

(Received February 9, 1998)

(Revision received March, 30, 1998) 